\title{
SIEMPRE QUEREMOS SABER QUIÉN HABLA
}

\author{
María Amoretti Hurtado
}

\begin{abstract}
RESUMEN
A partir del conocido artículo de Michel Foucault "¿Qué es un autor?" se ilustra la problemática actual de esta función en diferentes textos hispánicos y costarricences, con el fin de escudriñar precisamente en esa "grieta" que, según Foucault, deja la desaparición del autor y en la que encontramos un interés cada vez más grande y menos disimulado por decir y saber quién habla.
\end{abstract}

\begin{abstract}
Michel Foucault's article "What is an author?" illustrates the issue related to the function of the author in different Hispanic and Costa Rican texts. The purpose is to look into the void that, according to Foucault, is left with the disappearance of the author and the growing and open interest on knowing as well as telling who is speaking.
\end{abstract}

La indiferencia por quién habla no es un rasgo que caracterice la manera en que uno habla o escribe

Michel Foucault

Asesorando la investigación de Rita Porras León sobre una de las novelas de Brice Echenique, a quien tuve el gusto de conocer en mis épocas de estudiante de posgrado en la Universidad de Montpellier, se me reveló de manera más diáfana -y quizá diferente-, lo que Foucault nos proponía casi dos décadas atrás en relación con la imagen del autor; pero también se me vinieron a la memoria viejas inquietudes y preguntas que habían quedado anotadas en el margen de ese artículo de Foucault y decidí entonces volver al texto para reciclar su contenido, apoyándome ahora en la totalidad del paradigma que ese filósofo francés develó precisamente al final de su obra: la subjetividad y las técnicas de gobernabilidad que ella implica.

El presente trabajo tiene como objetivo reunir las reflexiones a las que esta relectura de Foucault me invita. Se encontrará aquí un resumen de algunas de sus ideas respecto de la noción de autor ${ }^{1}$, publicadas en un artículo suyo titulado "What's an author?"; se trata de un resumen comentado que -partiendo de una traducción nuestra- se adereza con una serie de observaciones, referencias cruzadas e ilustraciones extraídas de mis propias investigaciones y de otras en las que he participado como asesora o directora. Todo ello con el propósito de facilitarle al 
lector no sólo información adicional, sino también, motivos para repensar, a partir de la noción de autor, algunos postulados y conceptos fundamentales en la moderna teoría literaria.

La revisión crítica que ahora propongo, se inició, no obstante, en un artículo publicado en Káñina a propósito de la obra de Magón ${ }^{2}$. Lo que en ese trabajo se iba acotando como curiosidades al margen (preguntas inquietudes, sugerencias) en notas de pie de página, aquí se desarrolla y se integra en el cuerpo mismo de las ideas de Foucault. A veces para confirmarlas y ampliarlas; otras, para refutarlas y contrastarlas con las posiciones que al respecto han asumido otros especialistas, con quienes estamos familiarizados, particularmente en los seminarios y cursos de Teoría Literaria que ofrece la Escuela de Filología, Lingüística y Literatura de la Universidad de Costa Rica.

El trabajo de Foucault que a continuación resumimos parcialmente, comentamos, comparamos, ilustramos y ampliamos, fue publicado inicialmente en Francia, en 1969 y luego traducido al inglés por Joseph V. Harari y publicado en 1979. Nuestro documento de base es el que aparece en el libro Crítica en Norteamérica.

Michel Foucault, dentro de su medular preocupación por las tecnologías de la subjetividad, no podía dejar de plantearse el problema del autor, como otra forma más de la constitución del yo, de un yo específico, en este caso, un yo llamado autor.

\section{¿Qué es un autor?}

Ante esta pregunta, que constituye al mismo tiempo el título de su trabajo, Foucault sugiere que la respuesta debe elaborarse a partir de un examen sobre la relación entre texto y autor y en la manera en que el texto apunta hacia esta "figura" que, al menos en apariencia, está fuera de él y lo antecede.

Según Foucault, la idea del autor, que normalmente aceptamos como una categoría dada, intemporal e irreductible, es más bien una función del discurso, la cual ha cambiado a lo largo de la historia. Es de este cambio de lo que quiere dar cuenta efectivamente el presente artículo, haciendo un análisis actuarial de la situación presente con respecto a la figura del autor.

Cuando se lleva a cabo la reconstrucción histórica de un concepto, un género literario o una escuela filosófica, estas categorías (géneros, escuelas) aparecen como relativamente débiles, secundarias, superpuestas como ornamentos, en comparación con la sólida y fundamental unidad de las nociones de autor y de obra. Es esa solidez de entidad "a priori", categoría dada de antemano, lo que hace de la noción de autor un concepto de manejo delicado, un ideologema fundante emparentado con ciertas técnicas de subjetivación. Por eso, para Foucault, la aparición de la noción de autor constituye el momento privilegiado del proceso de "individualización" en la historia de las ideas, del conocimiento, la Literatura, la Filosofía y las Ciencias.

Los perfiles de la noción moderna de autor comienzan a hacerse visibles con la postulación formalista de la regla de la inmanencia, la cual se puede traducir como una indiferencia con respecto al que está hablando, cualquiera que este sea. Por lo tanto, la regla de la inmanencia en el fondo no es otra cosa que un principio ético de la escritura contemporánea: no puedo 
juzgar al autor por lo que escribe, ni juzgar la obra por su autor. Conocido como "amoralidad del arte", este principio ético será posteriormente apoyado por una fenomenología de la escritura que la describe como un mecanismo mediante el cual el yo se desposesiona de sí mismo ("se deprendre de soi"); de ahí que Foucault afirme en otro momento que "uno escribe para convertirse en otro distinto de quien es" 3 .

Al igual que Nietzsche, Foucault considera que el hombre es una invención, que el ser humano está formado por un conjunto de normas, estatutos y regulaciones definidas por las costumbres, prácticas e instituciones. Cada ser humano es entonces un compuesto de naturaleza y cultura. En palabras de Gilles Deleuze, amigo y cófrade intelectual de Foucault, las consecuencias de las anteriores afirmaciones son las siguientes:

Decir algo por cuenta de uno mismo es muy curioso. Porque uno no habla por sí mismo cuando se considera un "Yo", una persona o un sujeto. Por el contrario, el individuo adquiere verdadero nombre propio mediante el más severo ejercicio de despersonalización, cuando se abre a las multiplicidades que lo atraviesan de pies a cabeza (Miller 1995: 262).

De ahí que la verdad sobre uno mismo, continúa diciendo Deleuze, "no es algo que esté allí, algo que se pueda hallar o descubrir, sino algo que hay que crear" (Miller 1995: 95).

El uno mismo debe construirse obligando al caos propio a convertirse en forma y para ello la escritura es el medio. Por eso, para él, la escritura es más bien un intento por modificar el propio modo de ser. La literatura, entonces, no es sino una forma de "experiencia interior", un espacio "daimónico", de encuentro con el destino individual. Esta experiencia interior debe iniciarse con un esfuerzo por excluir al sujeto, con un intento por ubicarse fuera de la subjetividad. La literatura sería entonces el mecanismo que revertiría la revelación especular lacaniana, haciendo posible el paso de la identificación a la desidentificación. Sería la "tachadura” (litura) a la que alude el propio Lacan en su juego poético de la lituratierra ${ }^{4}$. Tachadura, borrón del fantasma o del señuelo que es la identidad del sujeto.

El problema del que escribe consistía antaño en apartarse del anonimato de todo; hoy es borrarse, borrar el propio nombre y alojar la voz propia en el gran murmullo anónimo de los discursos actuales (Miller 1995: 219).

Estas ideas sobre la escritura Foucault las recibe de la estética propulsada por los escritores de su época, escritores como Blanchot, Bataille, Roussel o Robbe Grillet. El aporte de Foucault reside en insertar esa estética dentro de una necesidad filosófica, puramente nietzscheana, de la búsqueda del "self".

Sin embargo, según el filósofo francés, en la literatura, el principio de inmanencia -de la muerte del autor, como diría Barthes (1987)-, jamás es aplicado realmente, a pesar de ser un concepto tan llevado y traído en la modernidad.

Para Foucault, la indiferencia por quién habla no es un rasgo que caracterice la manera en que uno habla o escribe. Es más bien una regla o principio que no asume la escritura como algo terminado, sino como una práctica y esta práctica está gobernada por necesidades institucionalizadas, entre las cuales está la de la pretendida indiferencia por quién habla; pero como se verá más adelante, esa misma mediación -la de las normas del comentario- puede producir el 
efecto contrario, borrando la búsqueda del "self" e instalando en su lugar una nueva identidad, otra más, de las tantas construidas por las técnicas subjetivantes que precisamente la escritura busca evadir.

Teóricamente, los dos principios básicos de la regla de la inmanencia son la autorreferencialidad y el despiegue autónomo del signo.

\section{La autorreferencialidad}

Según este principio la escritura se refiere solamente a ella misma y, por lo tanto, no tiene dimensión expresiva. Es más, ella se desarrolla como un juego que invariablemente va más allá de sus propias reglas y es capaz de transgredir sus límites; por eso la escritura se identifica más que con su interioridad, con el desarrollo de su propia exterioridad, puesto que escribir es crear un espacio en el que el sujeto que escribe desaparece constantemente.

Para comprender a cabalidad esta última afirmación que Foucault ha explicado ya, en un plano filosófico, como parte de un proceso de búsqueda del "self" que debe comenzar por liberarse de toda identidad impuesta por las técnicas de subjetivación a las que la sociedad nos somete, es menester también referirnos a lo que acontece en el plano meramente lingüístico; podríamos, por ejemplo, recurrir a la diferenciación básica que normalmente se hace entre el discurso oral y el escrito.

Para ello, las explicaciones de Cristina Dalton en su libro Lengua y Literatura. Ensayos didácticos (1991), nos vienen muy al pelo, pues en esta cuestión la autora resume, coteja y comenta las conceptualizaciones de destacados investigadores en este campo, facilitándonos así las cosas.

Apoyándose en Rodino, Dalton destaca que la diferencia sustancial entre el discurso oral y el escrito es que este último se desliga de la situación inmediata que lo produce y que este desligamiento es precisamente lo que altera tanto la estructuración como el funcionamiento de la comunicación escrita en relación con la oralidad. Este desligamiento de la situación trae, entre otras consecuencias, el recrudecimiento del problema de quién habla entonces. Transcribimos a continuación uno de los segmentos del mencionado libro:

\footnotetext{
Sin embargo, si tuviéramos que generalizar, afirmaríamos que en la gran mayoría de los textos escritos se agudiza la cuestión de "quién habla". El discurso oral, como hemos dicho, está firmemente arraigado en su situación originaria: tenemos delante a un hablante a quien identificamos de alguna manera (aunque sea mediante señas impersonales como un uniforme) y quien nos orienta en nuestra comprensión con sus gestos, el tono de su voz y otros signos suplementarios; también él forma parte de una totalidad circunstancial que, como autoridad última, limita las interpretaciones posibles. Pero, como hemos dicho, el texto escrito no está enmarcado dentro de tal totalidad; quién, entonces, es la autoridad última que limita su interpretación? (Dalton 1991: 59).
}

Ante el desligamiento del contexto, la escritura debe crear, entonces, su propia exterioridad, desarrollarla -como dice Foucault- y lo hará a través de sus propias reglas. Dalton lo explica así: 


\begin{abstract}
Antes de proseguir, detengámonos para examinar un poco más esta cuestión. El problema de quién habla siempre es complejo, aun en el discurso oral, porque las mismas estructuras del lenguaje natural y del contexto cultural lo hacen así. En primer lugar, todo discurso se desdobla para formar dos dimensiones, que la lingüística llama la enunciación y el enunciado: el acto de producción, por un lado, y el producto, por otro. Esto quiere decir que ciertos elementos del discurso apuntan en dos direcciones a la vez: las circunstancias de su producción y hacia un mundo creado por él. Entre ellos, el pronombre "yo" (que es el que nos interesa ahora) representa, dentro del discurso, a un hablante exterior a él; a la vez, forma parte de una serie de significados creados por el discurso -o, en otras palabras, en el mapa significativo creado por el discurso, ocupa el lugar opuesto al "tú"-. En consecuencia, la identidad del "yo" que aparece en el discurso es incierta: no se puede desligar de una persona real (la que habla), pero nunca puede ser ella tampoco (Dalton 1991: 59).
\end{abstract}

Dice Dalton que por esa razón, en el discurso escrito particularmente, se nos dificulta saber quién habla, saber de quién son esas palabras; mientras que "en el discurso oral, la duda queda solventada, en la mayoría de los casos, por el recurso a la globalidad de la situación: la autoridad última es el que habla en su situación, y deriva su identidad del contexto (Dalton 1991: 59-60).

Después de estos señalamientos, Dalton tiene que llegar necesariamente a la noción de texto, confirmándose así lo que nos explicaba Foucault acerca de la función autor y su relación con nociones conexas sin las cuales no podría sostenerse. Dice Dalton:

Cuando nos enfrentamos al texto, en cambio, falta esta situación, y buscamos el marco de referencia en algo que la sustituye: la globalidad del texto, que viene a ser, por decirlo así, el hablante último (Dalton 1991: 59-60).

De modo que la imagen del autor es, como dice Foucault, un efecto y una función del propio discurso, ya que esa globalidad del texto a la que alude Dalton es el principio de unidad, del cual se desprende a su vez "el dador del relato". Esa globalidad, por otra parte, es de naturaleza estrictamente lingüística y reemplaza la coherencia contextual o circunstancial del discurso oral. De modo que nuevamente desembocamos en la noción de lenguaje como valor predominante y en la autonomía de esa globalidad en su carácter estrictamente lingüístico. Estamos pues ante una argumentación entimemática tal y como está explicando Foucault la aparición de la imagen del autor, como un constructo del propio discurso teórico de la literatura, pero coproducido al mismo tiempo por el funcionamiento del texto dentro de una práctica (institucionalizada), es decir, del hecho de que ese discurso escrito se pone a circular según determinados mecanismos sociales que regulan no sólo su modo de producción, sino también su modo de distribución y consumo.

De la autonomía y autorreferencialidad de la escritura, que la teoría ha establecido, se deriva la desaparición del autor. Es eso lo que Foucault quiere decir cuando afirma que la escritura se identifica más con el desarrollo de su exterioridad que con su propia interioridad. De ahí también la idea de la desposesión experimentada por el yo (el self) que escribe.

Para lograr el efecto de la desaparición del autor, el sujeto escribiente establece una serie de mecanismos entre él y lo que escribe, con el fin de cancelar los signos de su particular individualidad. Pero esos mismos mecanismos producen en su lugar al "hablante básico" que emerge de la globalidad de la situación, producto del mismo discurso, elemento creado por el propio texto. Lo resultante es que la marca del escritor se reduce nada más que a la singularidad de su ausencia. El debe asumir el papel del difunto en el juego de la escritura. Pero su muerte 
puede llegar incluso a provocar otro homicidio más: la liquidación también del propio hablante básico del texto, como se verá en el siguiente apartado.

\section{Despliegue autónomo del signo}

Por eso, si antes el escribir perpetuaba en la inmortalidad y era un esfuerzo por eludir la muerte, como en el caso de Scherazzada; hoy posee el derecho de matar, el derecho de ser el asesino del autor. Entonces, escribir es un sacrificio y una inmolación: una muerte. La narrativa es una muerte aceptada o buscada voluntariamente. Pero esta muerte puede llegar incluso hasta intentar liquidar al propio hablante básico del texto, para crear el efecto de una autonomía sin precedentes: el vacío, la nada, la pura presencia del lenguaje.

A propósito de Scherazzada, a quien acabamos de recordar unas líneas antes, hay un texto en la literatura costarricense que, partiendo de esa teleología la destruye. Es un texto que ilustra plenamente el mero despliegue del lenguaje y la aniquilación, ya no tanto del autor o su imagen, sino la destrucción misma de la instancia narradora a través de la cual el lector ha tomado conocimiento del texto. En una publicación en Káñina, ya nos referimos ampliamente a esta obra?. Se trata del cuentario de Rafael Angel Herra titulado El genio de la botella. En él, un perro que por accidente libera de su botella a un genio violento y malhumorado, se ve obligado a entretenerlo con el relato de historias a fin de conservar la vida. Al final del libro el lector descubre que la instancia narradora no existe, que es producto de otra y que ha sido el propio genio quien, en su hastío de siglos de encierro en la botella, ha creado a su perro salvador y lo ha obligado a contarle esas historias. Así, el relato se autoaniquila en función de su significación inversa. Es decir que, en este "relato de relatos", como lo subtitula su autor, al liquidarse la instancia narradora, el propio texto mata a su padre, es un texto parricida. Y sin embargo, sobrevive el relato. Es entonces posible un relato sin locutor. Pero en realidad no es así. Lo que ocurre es lo siguiente: tanto el locutor como lo que cuenta son producto de la imaginación de otro locutor de cuya función narradora no tenemos noticia sino hasta el final del relato; por una serie de subterfugios narrativos, al estilo del cuento "Las ruinas circulares" de Borges, esa instancia se oculta y como un efecto más de la ficción, el signo se desprende de su propia situación e inicia un viaje de orfandad. De modo que si el relato del narrador fantasma sobrevive lo hace por el simple hecho de que ya el lector ha tomado posesión del relato, ha entrado en su conocimiento y esto es un hecho irreversible. Texto a todas luces posmodernista en el que se debaten las cuestiones más polémicas de la actual teoría literaria, como las planteadas por Foucault en este artículo: despliegue funcional del principio de inmanencia y de la autonomía del arte.

El extremo más acabado de esta autonomía lo representa $A$ flote, novela suscrita por Polo Moro en una publicación de Ediciones Universal, Florida (1996). En ella encontramos un homicidio más: el del lector.

En esta novela no hay propiamente hablando "dación del relato". Al penetrar el mundo ficcional nos encontramos de repente no leyendo, sino escuchando la lectura que un personaje hace a otro del libro que tenemos en nuestras manos. De esa forma, nos damos cuenta de que el texto nos ignora completamente en nuestra condición de lectores y nos coloca en una comprometedora situación de "voyeurs", como si miráramos subrepticiamente a través del ojo de una cerradura situaciones de cuyo conocimiento no tenemos derecho. Así, en A flote, el acto de leer se modifica 
tanto en su naturaleza fáctica como en su calificación ética, ya que al enterarnos de una situación de cuyo conocimiento no tenemos licencia ni autorización, nuestra relación con el texto se convierte de repente -y sin advertencia alguna-, en una presencia clandestina inconfesable. Todo testimonio de nuestra parte acerca de lo que allí presenciamos es no sólo completamente inválido, sino además autoinculpante. Cualquier declaración que hagamos al respecto nos convierte en parte confesa de una infracción. Cualquier cosa que digamos puede ser usada en nuestra contra.

Así, el comentario mismo queda silenciado. No es posible crítica alguna, pues el texto nos amordaza con el silencio, ya que nadie podría aceptar el hecho de haberlo leído sin declararse, por ese mismo hecho, culpable del delito de una violación, la violación de haber penetrado en una conversación privada a la que no hemos sido llamados a participar, ni siquiera como oyentes.

En cualquiera de los dos casos, autor o lector, la escritura asesina en función de su autodeterminación. La autodeterminación lleva, en principio y correlativamente, a la libertad interpretativa; pero también puede derivar en un hermetismo impenetrable del texto, reduciendo la interpretación al absurdo, al grado cero del comentario, como se vio en el caso anterior en el que el texto es tan él mismo que resulta imponderable, inexpugnable e inenunciable desde el exterior.

Los homicidios cometidos por la escritura están, pues, en función de su autodeterminación.

La inmanencia y la autorreferencialidad (despliegue autónomo del signo) son entonces nociones que pretenden reemplazar la privilegiada posición del autor; sin embargo, actualmente, parecen conservar ese privilegio suprimiendo el real significado de su desaparición. Por otra parte, la noción de escritura contiene las nociones precedentes al plantearse ella misma como el mecanismo que las engendra.

Para Foucault es precisamente la noción de escritura la que ha bloqueado la posibilidad de medir cabalmente la desaparición del autor, oscureciendo y ocultando el momento de esta desaparición y sutilmente preservando la existencia del autor. Sutileza de la que en la actualidad ya no se tiene gran cuidado, como lo veremos más adelante.

Aplicada rigurosamente, esta noción nos debería permitir, no sólo vencer las referencias del autor, sino también, situar su reciente ausencia.

Corrientemente empleada, la noción de escritura no tiene que ver con el acto de escribir ni con la indicación -sea ésta síntoma o signo- de un significado que alguien haya querido expresar. Tratamos, con gran esfuerzo, de imaginar la condición general de cada texto: tanto del espacio en que este se dispersa como el tiempo en el que se desarrolla. En el uso común, sin embargo, la noción de escritura parece trasladar las características empíricas del autor hacia una anonimia trascendental ${ }^{8}$.

Nos contentamos con borrar las marcas más visibles de la existencia empírica del autor, jugando con dos modos -totalmente antagónicos el uno del otro- de caracterizar la escritura: la aproximación crítica y la aproximación religiosa de la escritura.

Darle a la escritura un estatuto de primera importancia parece ser -comenta Foucault- el modo de retraducir, en términos trascendentales, tanto la afirmación teológica de su carácter sagrado como la afirmación crítica de su carácter creativo. Admitir que la escritura está sometida a la prueba del olvido o la represión, gracias a la historia que la hizo posible, parece representar, en términos trascendentales, el principio religioso del significado oculto (el cual requiere interpretación) y el principio crítico de las significaciones implícitas, las determinaciones silenciosas y los contenidos oscuros (los cuales hacen surgir el comentario). 
En el libro de Eco titulado Los límites de la interpretación (1992) se nos brinda una clarísima explicación sobre esta relación entre la aproximación crítica y la aproximación religiosa de la escritura, derivando audaces homologías entre la semiosis hermética, el deconstruccionismo derridiano y la ventrilocución norteamericana de las teorías del muy conocido filósofo francés, Jacques Derrida. Así explica Eco el nacimiento de la semiosis hermética:

\begin{abstract}
Fascinada por el infinito, la civilización griega elabora, junto al concepto de identidad y no contradicción, la idea de la metamorfosis continua, simbolizada por Hermes. Hermes es volátil, ambiguo, padre de todas las artes pero dios de los ladrones, iuvenis et senex al mismo tiempo. En el mito de Hermes se niegan los principios de identidad, de no contradicción, de tercero excluido, las cadenas causales se enroscan en sí mismas en espiral, el después precede al antes, el dios no conoce fronteras espaciales y puede estar, bajo formas diferentes, en lugares distintos en el mismo momento (1992: 51).
\end{abstract}

A partir de allí, Eco afirma que el pensamiento hermético transforma todo el mundo en fenómeno lingüístico y, al mismo tiempo, sustrae al lenguaje (le roba) todo poder comunicativo, es decir, se inaugura la deriva interpretativa, el deslizamiento continuo del sentido. Rasgos reconocibles en muchas concepciones posmodernas de la crítica, especialmente en el deconstruccionismo.

En muchas políticas interpretativas de la actualidad se puede constatar la herencia hermética, sobre todo en la idea del secreto y la conjura, es decir, en la idea de una escritura en la que el autor no sabe de lo que está hablando porque el lenguaje habla en su lugar; por lo tanto, para salvar el texto, dice Eco, se necesita de un Superhombre que comprenda la verdad de éste y actúe sobre él sospechando que cada línea oculta un secreto. Estos lectores "elegidos" son los que entienden que el verdadero significado de un texto es su vacío y que la semiótica es un complot de quien quiere hacernos creer que el lenguaje sirve para la comunicación del pensamiento.

Aparte del directo y sarcástico ataque al deconstruccionismo y sus prácticas interpretativas que parece inspirar el grueso de este libro de Eco, su autor pone de relieve la exagerada atención y privilegio que muchas teorías literarias posmodernistas han dado a la noción de escritura. El siguiente fragmento tomado del mismo libro de Eco, sintetiza de manera magistral, la valoración que hace Foucault sobre el concepto de escritura como ausencia. En ella Eco transcribe un comentario de John Wilkins relativo a todo primer encuentro del hombre con la escritura:

Cuán extraño debió resultar este Arte de la Escritura en su primera Invención lo podemos adivinar por los Americanos recién descubiertos, que se sorprendían al ver Hombres que conversaban con Libros, y a duras penas podían hacerse a la idea de que un Papel pudiera hablar (...).

Seguidamente Eco agrega para nosotros su propio comentario para contrastar esa extrañeza de la que habla Wilkins, frente a la familiaridad con que el hombre moderno vive la escritura, familiaridad que se transforma en una especie de culto en el que la escritura es un demiurgo aceptado y reverenciado:

Seguramente esta página de Wilkins suena diferente de otras páginas de nuestro tiempo donde la escritura se toma como ejemplo supremo de semiosis, y todo texto escrito (o hablado) se considera una máquina que produce una "deriva infinita del sentido". Tales teorías contemporáneas le 
objetan indirectamente a Wilkins que, una vez separado de su emisor (así como de su intención) y de las cincunstancias concretas de su emisión (y por lo tanto del referente al que alude), un texto flota (digámoslo así) en el vacío de un espacio potencialmente infinito de interpretaciones posibles (Eco 1992: 9-10).

Así, en la actualidad, imaginarse la escritura como ausencia parece ser una simple repetición, en términos trascendentales, tanto del principio religioso de lo inalterable y de la interminable tradición, por una parte; y por otra, del principio estético de la sobrevivencia de la obra, su perpetuación más allá de la muerte del autor y su enigmático exceso en relación con éste ${ }^{9}$, como lo acabamos de ilustrar con las explicaciones de Eco en relación con la teoría hermética y el deconstruccionismo ${ }^{10}$.

El principio estético de la sobrevivencia de la obra y su transcendencia, tiene otra justificación teórica que la explica a partir de su carácter de práctica institucionalizada. Antonio Gómez Moriana, sociocrítico de la Universidad de Montreal, aborda la universalidad del texto como un hecho paradójico. Si bien su punto de vista considera la ruptura de las circunstancias concretas de emisión del signo y su separación de la intención inicial de su emisor, no llega por ello al extremo de plantear la posibilidad de una "deriva interpretativa" ni un "deslizamiento continuo del sentido", como lo lamenta Eco de algunas posiciones contemporáneas.

Para Gómez Moriana, en la producción del texto se presenta una situación comunicativa "ideal", según la cual se supone que el emisor está consciente del papel de cada parte en el todo, como de las evocaciones que cada elemento del todo puede suscitar entre sus destinatarios o receptores. En cuanto a la recepción, ella supone un lector "ideal" que comparte con el autor todas estas informaciones y esto sólo es posible con un auténtico interlocutor que pertenezca al mismo grupo social y que tenga el mismo patrimonio cultural del emisor. Esta situación ideal, corriente en la comunicación ordinaria y cotidiana, no existe en la literatura. Hay que distinguir, sin embargo, diferentes grados de distanciación de esta situación ideal. Igualmente se deberá tener en cuenta que la literatura, en tanto práctica institucionalizada, difunde un texto más allá de las fronteras lingüísticas y culturales, geográficas e históricas de su producción, rompiendo con ello esta situación que se ha llamado ideal desde un punto de vista puramente comunicativo y no precisamente literario.

Es a esta ruptura a lo que Gómez Moriana denomina "paradoja del hecho literario". Esta paradoja se formula como la tensión que existe entre la especificidad del texto en su situación primera de enunciación (en el enclave geográfico, sociocultural e histórico que caracteriza su producción) y su difusión; conforme a lo que este autor llama "vocación universal de la literatura".

Así, todo texto auténticamente literario (que además comporta una doble determinación, según el término usado en teoría de la comunicación para designar la comunicación paradojal) tiene una doble dimensión. Esto deberá considerarse como un elemento de su literariedad. Si se acepta esta hipótesis, habría que definir este elemento como aquel que representa la tensión esencial al hecho literario, entre un acto de emisión situado en el espacio y el tiempo y un modo de recepción incontrolable en el momento del acto primero de emisión. La ruptura de situaciones contextuales va a provocar la diversidad de medios en los que será recibido y tendrá como resultado irremediable que el lector no responda ya al destinatario ideal que el autor había 
imaginado al escribir su libro. De modo que en el momento de la edición, publicación, del texto, el autor hace algo más que vender sus derechos: renuncia a ellos, a su propia autor-idad sobre el texto.

Pero de la tensión que el mismo Gómez Moriana redefine como "comunicación paradojal" podemos deducir también una tercera consecuencia; esto es, que el emisor original del acto de enunciación que se sitúa en un espacio y tiempo determinados no puede "desaparecer" radicalmente, al menos algo, una nueva entidad, ocupará ese vacío de su ausencia. Ya volveremos a este asunto.

Foucault es bien consciente de esto y por eso advierte que no obstante este uso de la escritura como ausencia, siempre se corre el riesgo de mantener los privilegios del autor bajo la protección del status de "a priori" que ella tiene. Este uso mantiene viva, en la gris iluminación de la neutralización, la interacción de aquellas representaciones que formaron una particular imagen del autor. La desaparición del autor, la cual desde Mallarmé, según Foucault, ha sido en forma constante un evento recurrente, está sometida a una serie de barreras trascendentales. Ahí parece existir una importante línea divisoria entre los que creen que todavía pueden localizar las rupturas o discontinuidades de hoy en la tradición histórica trascendental del siglo XIX y aquellos que tratan de liberarse de una vez por todas de esa tradición. No basta, sin embargo, la vacía afirmación de que el autor ha desaparecido ${ }^{11}$.

Por la misma razón, continúa Foucault, no es suficiente continuar repitiendo (después de Nietzsche) que Dios y el hombre murieron de muerte común, una misma muerte. Más bien, deberíamos ubicar el espacio que quedó vacío con la desaparición del autor, seguir la distribución de las brechas y aberturas y buscar las grietas que esta desaparición deja al descubierto. Esa es nuestra intención.

Para ilustrar esto, nos viene de perlas el trabajo de investigación que mencioné al inicio de este artículo y que tuve la ocasión de asesorar. Como dije entonces, se trata del estudio que sobre una de las novelas de Brice Echenique elaboró Rita Porras en la Universidad de Costa Rica. La investigación de Porras contestaría la pregunta que ha planteado Foucault en términos de la necesidad de ubicar el espacio que quedó vacío con la desaparición del autor y la cuestión que nosotros nos planteábamos a raíz del concepto de "comunicación paradojal" que nos ofrecía Gómez Moriana, en el sentido de que ese espacio vacío está siempre ocupado por una entidad sustituiva de la figura del autor tal y como tradicionalmente se la ha comprendido. Cuál es la naturaleza de esa entidad y cómo funciona en relación con el texto, es lo que la investigación de Porras nos podría iluminar.

La novela de Echenique en cuestión se titula La vida exagerada de Martín Romaña. Porras la resume de la siguiente manera:

Se ofrece al lector como 'un diario de navegación' donde se encuentran anotadas (a posteriori) peripecias significativas de la vida del escritor del diario (Martín Romaña) y sus reflexiones -sentimentales las más de las veces, unas cuantas irónicas- sobre los acontecimientos vividos. El texto, por lo tanto, es el resultado de un largo y difícil proceso de interiorización de eventos (crisis positiva) que culmina con su escritura (Porras 1995: 41).

Esta sinopsis de la diégesis, Porras la presenta como el plano de lo ficticio y lo contrapone al plano de lo real que circunscribe al texto dibujándole sus márgenes. En ese plano de lo real circunscribiente, lo que se destaca de modo relevante como su borde, es precisamente la 
imagen del autor, pues la novela se ofrece con una contraportada en la que se destaca la figura de Echenique más que la del propio texto. En esa presentación se pondera que su autor ha vivido situaciones exageradas, que tiene gracia para contarlas y que en esa novela se recogen precisamente esas situaciones narradas en ese estilo humorístico que lo caracteriza. De modo que se plantea una clara homología entre el personaje de ficción, Martín Romaña, y su autor, Brice Echenique.

Al evidenciar en su estudio estas equivalencias, Porras pasa a explicar las condiciones de posibilidad de éstas y, al hacerlo, confirma lo que Foucault afirma acerca de la supervivencia de la figura del autor, su ubicación en la ruptura de un constructo discursivo y su función de marcar los bordes y caracterizar el texto; a pesar de la sonada y jurada autonomía del texto en nuestros días. Dice Porras:

\begin{abstract}
Existen quienes se interesan en la literatura porque la consideran un signo más de la compleja personalidad del escritor. A ellos les importa el ser humano que fue capaz de componer una obra literaria de determinadas virtudes (...) y ponen atención en el grado de referencialidad biográfica de la novela haciendo un inventario de los temas, espacios, personajes, nombres y fechas comunes a la vida del autor y al mundo imaginario de la obra. También están los que se desplazan a través de los complejos hilos de la novela buscando ver manifestarse en ellos la psiqué del artista (lectura psicoanalítica) (...) Otros, trascienden el concepto tradicional de autor (el que escribe el libro) en un intento por conocer la época histórica a través del texto. Para ellos el libro es un verdadero documento en su sentido de fuente de la investigación histórica, de modo que todo dato social enunciado en el texto es al mismo tiempo dato histórico de la sociedad que se ve ahí reflejada en su sentido más estrictamente peculiar (...) Para él, el autor tiene importancia en tanto nexo entre un momento socio-histórico dado (fecha y lugar de nacimiento) y la realidad histórica en su totalidad. También suele interesar el autor desde el punto de vista de una tradición filosófica dada. El autor es primeramente un pensador que transmite sus ideas mediante textos más o menos ficcionales (...) Para este grupo, la obra interesa en cuanto manifestación parcial del ideario del autor (...) También debe considerarse la perspectiva humanista del autor. Para los lectores muy involucrados con esta postura, el buen escritor es un hombre excepcional que enriquece con su obra el acervo cultural de la humanidad (Porras 1995: 48).
\end{abstract}

Obsérvese cómo a cada definición de autor, Porras hace corresponder también una idea de texto.

Pero luego de explicar estas consideraciones sobre la figura del autor como propias de la historiografía literaria, Porras pasa a explicar el uso de la función autor en el mercadeo del libro y sus efectos en el contrato de lectura. Son precisamente estas consideraciones las que vendrían a complementar aquí las reflexiones de Foucault ilustrándolas, además, de manera muy clara. Explica Porras:

(...) lo cierto es que la sociedad humana ha generado el libro y con él el mercado del libro. Un mercado que necesita hacer del libro una necesidad, independientemente del valor de uso o de cambio que posea. Un mercado que necesita promocionar el libro en un medio competitivo, haciendo uso de todas las técnicas de mercadeo conocidas y por conocer.

(...) también los libros necesitan de una marca, algo que les permita posesionarse de un área del mercado y efectuar allí su dinámica del intercambio, producción, promoción y comercialización. La marca del libro se ha construido mediante la acentuación de aquel rasgo de su identidad que mejor satisface su demanda (1995: 55).

Y Porras explica cómo en la línea promocional de la novela en cuestión esa marca es precisamente la figura del autor; ella es la clave para satisfacer esa demanda, junto con otros dispositivos como: título, temática, estilo, casa editorial que lo respalda y calidad de la edición. 


\section{Así, la promoción de la contraportada expone lo siguiente:}

Brice Echenique es, hoy por hoy, una de las personalidades literarias más fascinantes dentro del ámbito de la lengua castellana. Su peripecia vital, sus raíces familiares, sus episodios personales llegan a nosotros a través de sus ficciones narrativas y de los frecuentes artículos que publica en las más importanes revistas y periódicos latinoamericanos ${ }^{12}$.

Si la promoción de este libro se sustenta en la imagen del autor, más que en cualquiera otro de los dispositivos señalados, es porque el editor considera que ese es el elemento solicitado por el mercado que lo recibe. Este razonamiento obliga a preguntarse qué es lo que tiene Brice Echenique que pueda ser vendible. Porras lo resume de manera muy aguda:

Es un hombre -no mujer. Es peruano y cosmopolita: nació en Lima -y no en barrio marginal de nombre desconocido. Luego, es latinoamericano, como Cortázar, Vargas Llosa, Sábato, Borges, Rulfo y Octavio Paz y... tiene una educación foránea -cursó estudios primarios y secundarios en distintas instituciones regidas por profesorado norteamericano e inglés..., luego, no es sólo latinoamericano (como Borges, como Cortázar, como...) tiene estudios universitarios -lo que equivale a "erudición y cultura" en nuestro medio. Y además conoce dos marcos conceptuales distintos: letras y derecho, lo que de paso lo hace poseedor de una profesión "liberal". Y dos tradiciones culturales también distintas: Universidad de San Marcos y la Sorbona. A los veinticinco años viaja a París -ciudad luz, ciudad eterna, foco cultural para Europa y América. Tiene una experiencia transcultural -no unicultural- ya que además vivió en Italia, Grecia y Alemania. Tiene el prestigio de un académico, pues ha sido profesor en Nanterre, la Sorbona, Vincennes y Montpellier (Universidad Paul Valéry). Posee además una producción literaria considerable (Porras 1995: 57).

La agudeza de estas observaciones de Porras reside en retratar de manera muy precisa la imagen no sólo del autor de La vida exagerada de Martín Romaña, sino además la imagen del autor ideal en la comunidad de lectores latinoamericanos, en el mercado literario de América Latina. Por otra parte, implícitamente se nos están ofreciendo los motivos del éxito que tiene hoy el género biográfico en todas sus modalidades, puesto que el editor está dando por un hecho el interés en conocer más acerca de la vida del autor y que es este interés el que va a inducir a comprar y a leer el libro.

Así pues, la problemática de la función autor continúa a pesar de la cacareada autonomía del texto, puesto que el asunto de los límites entre ficción y realidad es todavía una diferencia que no se ha asumido completamente a pesar de la teoría literaria y de los avances de la semiótica. La misma autora de esa investigación se devuelve a la tradición del humanismo para explicarse la necesidad de la referencia al autor sobre la que la contraportada de la novela sienta su promoción:

Un lector que enfrenta por primera vez a un autor, adopta una serie de conductas típicas de esta circunstancia. Sus espontáneas preguntas son: ¿quién es usted?, ¿qué grado de relación guarda conmigo?, ¿qué es lo que ha escrito usted?, ¿cuál es la propuesta que me hace?, ¿qué tipo de respuesta quiere de mí?

Entre autor-texto y lector se establece en el primer momento de contacto un incesante y casi inacabable diálogo que continuará reproduciéndose en su conciencia hasta que su sentido se agote. Porque el texto fue programado para contestar esas preguntas. 
Seguirá siendo un desconocido -si me niego a leer su biografía- pero al mismo tiempo ya no lo será tanto, porque me he expuesto a su gesto. Esa propuesta ante la vida que representa su escritura, es algo que me atañe, porque yo también soy un ser vivo que siento y respondo a las condiciones de mi propia existencia. Podré negarle o no negarle el saludo, podré negarle o no negarle la mirada, pero ya no podré negar la conciencia de conocer su existencia por medio de su obra.

He sido interpelado. Alguien me habla. Y aún mi silencio sería una respuesta.

$$
(\ldots)
$$

En ese trabajo incesante de construir la propia identidad (¿quién soy?), el autor de un texto que hemos elegido para leer es un punto de referencia que tendremos que ubicar y desde el cual nos ubicaremos en el mundo, lo mismo que se ubica un río, un volcán en la totalidad de una geografía (Porras 1995: 51-2).

O sea, que Foucault tiene razón, la escritura es una experiencia del "self", pero al mismo tiempo -agregamos nosotros- lo es también para el lector; ya que su lectura está motivada precisamente por eso mismo: para hacer él también una experiencia del "self" frente al tú que lo interpela y por relación a éste. Pero... ¿de qué tipo de self estamos hablando en este momento?

Se escribe para ser otro, dice Foucault, pero las reglas del consumo pueden hacer de esta experiencia un conflicto, enroscándola hacia su negación; es decir, hacia un self todavía más alienado y más ajeno al auténtico: el self comercial creado por el mercado promocional de la literatura. En el paratexto o en las otras convenciones intertextuales, se neutraliza la desposesión buscada por la escritura al orientar la lectura hacia la búsqueda de esa figura híbrida que se construye entre el autor real y el dador del relato: la imagen del autor como producto de las leyes del mercado. Al convertir la imagen del autor en una mediación, se la transforma en valor de cambio y con ello se la inserta perfectamente en el sistema económico de la sociedad de consumo.

Ese self comercial no solo repite los principios de gobernabilidad subjetiva de los que se intenta escapar, sino que los agudiza llevándolos hacia sus extremos.

De esta forma Porras se afilia al grupo que intentando manejar los textos desde su principio de inmanencia, debe rendirse ante el efecto de la función autor y no puede efectivamente asumir la indiferencia por la pregunta de quién habla a la que obliga la noción de ficción.

La diferencia entre biografías ficcionalizadas o ficciones biográficas no parece ser tal, dice Porras, cuando se intenta la captación del sentido de la novela como una propuesta que Brice Echenique por los medios estéticos plantea al mundo. De ahí que la estética se defina en términos de la ética del autor, del enigmático propósito que esa imagen inscribe en el texto, aunque la relación sea, como se apresura a aclararlo su autora, de contenido a forma. Este comentario de nuestra parte no es desvalorizante de la perspectiva de Porras, sino más bien concurrente con nuestros propósitos hermenéuticos, como se verá más adelante.

En la novela objeto de esa investigación, La vida exagerada de Martín Romaña, la presencialidad del autor se da desde el sistema paratextual, pero el mismo problema se presenta en aquellas en las que la instancia narrativa se confunde con la voz autorial, como es el caso de la mayoría de los relatos de Magón, por ejemplo ${ }^{13}$; nos referimos a la problematización del canon ficcional y sus bordes con la realidad. 
Los textos de Magón se caracterizan por la fuerte presencialidad de la imagen del autor y esto no se da allí por la acción de ningún paratexto, sino más bien por recursos intratextuales, particularmente por el uso de la ironía.

La presencialidad del autor es ineludiblemente convocada por el discurso irónico gracias a las razones que exponemos a continuación con la ayuda de las investigaciones de Linda Hutcheon (1981: 140-55).

Según esta autora, la presencia del tropo irónico subraya la postulación necesaria tanto de la intención del autor-codificador como del reconocimiento del lector-descodificador. Por eso, todo texto irónico hace que el acto de lectura se dirija más allá del texto (como unidad semántica o sintáctica), hacia una descodificación de la intención evaluativa, por lo tanto irónica, del autor.

Cuando se trata de un tropo como la ironía, continúa Hutcheon, no es posible entonces ignorar la decisiva importancia de la intencionalidad y de la recepción del texto. Al ser la ironía una estructura antifrásica (oposición entre lo que se dice y lo que se quiere dar a entender) y una estrategia evaluativa (juicio logrado por una inversión semántica), ella implica una actitud del autor-codificador en relación con el texto mismo.

Así, desde que se admite la ironía como tropo, ello presupone correlativamente el reconocer la pertinencia de las nociones no sólo de norma, sino sobre todo de intencionalidad; noción esta última que -como lo hemos venido comentando a lo largo de este artículo- la ética del moderno concepto de escritura debe pasar por alto.

Por eso, para Catherine Kerbrat-Orecchioni (1980: 108-24), el análisis de todo texto irónico plantea numerosos problemas e implicaciones teóricas: Entre ellas:

1. Las complejidades inevitables del concepto general de la intencionalidad.

2. El asunto de la competencia del lector.

3. La polaridad manipuladora del autor.

Entre esos problemas y complejidades intentamos abrirnos paso en nuestra investigación sobre los textos de Magón, en la que el mayor reto se da al intentar un análisis al margen de las sagradas convenciones teóricas de la ficción que dominan la interpretación contemporánea ${ }^{14}$.

Tanto Porras como yo intentamos mantenernos también a flote justo en la grieta de la ambigüedad que funda un límite tan dudoso como el que ciertas teorías de la literatura pretenden establecer entre la ficción y la realidad.

$\mathrm{Al}$ igual que Foucault, pienso que es justamente en el examen (reexamen) de la función autor que ese límite muestra su mayor fragilidad.

Manuel González Zeledón le dio un nombre a la brecha; la llamó "Magón", su nombre de autor.

Virgilio A. Mora Rodríguez con su "Polo Moro", le da nombre más bien al puente que tiende entre los dos territorios separados por esa brecha, revelando con detalle el nacimiento de la función autor a través de su propio suicidio. Gracias a esta inmolación, sus textos hacen patente lo que Foucault y Nietzsche afirman, que la realidad y su verdad son una pura invención, a las cuales antecede la mayor de todas ellas: el sujeto y la identidad.

Por eso, ante el espectáculo de la ficción, nosotros, los lectores, también ficcionalizamos el deseo, ocultando a duras penas la curiosidad de saber quién habla, mediante una indiferencia que cada día es peor simulada, tanto en la creación como en la crítica. 


\section{Notas}

1. Digo algunas, pues en el presente trabajo no abarco la totalidad del artículo "What's an author?" de Foucault, cosa que sí hago en una publicación anterior. Véase Amoretti 1997. "Autor y autoridad... cuestión de principios". Káñina. 21(2).

2. Me refiero a mi artículo anteriormente citado: “Autor y autoridad... cuestión de principios".

3. Foucault citado por James Miller (1995: 47) en La pasión de Foucault. Buenos Aires: Editorial Andrés Bello.

4. Jacques Lacan. 1971. Litterature. $\mathrm{N}^{\circ}$ 3. Hacemos referencia al jugoso comentario que hacen Manuel Picado y Ronald Solano en torno a este texto de Lacan en la revista de la Asociación Costarricense para la Investigación y el Estudio del Psicoanálisis (ACIEPs). 1995. "De litera, litura". Inscribir el pscicoanálisis. 4: 169-79.

5. Empleamos el término inglés "self", por una mera comodidad, ya que resulta más sintético que la expresión perifrástica del "uno mismo".

6. El destacado es nuestro.

7. Ver "Tres niveles intertextuales por los seis lados del cubo de la escritura". Káñina. 19(1), 1995.

8. Ver el concepto de intertextualidad de Bajtín y su anonimia universal en Estética de la creación verbal. México: Siglo XXI. 1982.

9. Recordar aquí Enfermedad mortal, una novela de Mora en la que la escritura libra al autor de esa esencial marca de lo humano: la muerte. En prensa en la Editorial de la Universidad de Costa Rica.

10. En las conclusiones de nuestro libro sobre Magón (todavía en proceso), volvemos sobre este asunto y lo ubicamos dentro de una historia de la evolución de los paradigmas teóricos en literatura, para poder explicar, entre otros aspectos, las condiciones de posibilidad de un tipo de textos como los de Magón.

11. Referirse a 1) Barthes "La muerte del autor" y 2) Derrida "Escritura, signo y juego". Ver bibliografía al final de este artículo.

12. Contraportada de La vida exagerada de Martín Romaña en su primera edición colombiana. 1986. Bogotá: Oveja Negra.

13. Ver "Autor y autoridad... cuestión de principios". Op. Cit.

14. Sobre esa investigación ya se han publicado tres avances en la revista Kañina. Además del ya citado "Autor y autoridad... Cuestión de principios", el interesado puede referirse a: "Nuevas propuestas metodológicas para una lectura diferente de Magón" y "Dos vivazos y un tonto en un certamen de mentiras". Ver bibliografía al final de este artículo.

\section{Bibliografía}

Amoretti Hurtado, María. 1990. Debajo del Canto (Análisis del Himno Nacional). San José: E. U.C.R. 
1993. Diccionario de términos asociados en teoría literaria. San José: E. U.C.R. 1995. "El odioso de Mora". Revista de Filología y Lingüística. 21(2): 7-16.

Publicaciones sobre Magón: "Nuevas propuestas metodológicas para una lectura diferente de los textos de Magón". Káñina.

1997. “Autor y autoridad.. Cuestión de principios". Káñina. 21(2).

1998. "Dos vivazos y un tonto en un certamen de mentiras". Káñina. 22(1).

Bajtín, Mijail. 1982. Estética de la creación verbal. México: Siglo XXI.

Barthes, Roland. 1974. "De la obra al texto". Por dónde empezar. Barcelona: Tusquets.

1978. El grado cero de la escritura. México: Siglo XXI.

1987. "La muerte del autor". Susurro del lenguaje. Traducción de C. Fernández. Barcelona: Paidós.

1970. S/Z. París: Seuil.

Booth, Wayne. 1978. La retórica de la ficción. Barcelona: Bosch Ed.

Derrida, Jacques. 1978. "Structure, sign and play in the discourse of the human sciences". Writing and difference. Trans. Alan Bass. Versión francesa: París, Seuil, 1972.

Dubois, Jacques. 1979. "Hacia una teoría de la institución”. Sociocritique. París: Nathan, Eco, Umberto. 1992. Los límites de la interpretación. Barcelona: Lumen.

1983. Tratado de semiótica General. Barcelona: Lumen.

Genette, Gérard. 1987. Seuils. Paris: Seuil.

Herra, Rafael. 1990. El genio de la botella. San José: E.U.C.R.

Hoek, Leo. 1981. La marque du titre. Dispositifs sémiotiques d'une pratique textuelle. La Haya: Mouton.

Hutcheon, Linda. 1981. "Ironie, satire, parodie. Une approche pragmatique de l'ironie". Poétique. 46: 140-55. 
Kerbrat-Orecchioni, Catherine. 1980. "L'ironie comme trope”. Poétique. 4: 108-27.

Miller, James. 1995. La pasión de Foucault. Buenos Aires: Ed. Andrés Bello.

Moro, Polo. 1996. A Flote. Florida: Ediciones Universal.

Porras, Rita. 1995. El humor en la vida exagerada de Martín Romaña. Tesis de Maestría: Universidad de Costa Rica. 
